\section{(2) OPEN ACCESS}

\begin{abstract}
- Additional material is published online only. To view please visit the journal online (http://dx.doi.org/10.1136/ thoraxjn-2019-213941).

For numbered affiliations see end of article.
\end{abstract}

\section{Correspondence to}

Dr Kevin Mortimer, Liverpool School of Tropical Medicine, Liverpool L3 5QA, UK; kevin.mortimer@|stmed.ac.uk

Received 9 August 2019 Revised 9 December 2019 Accepted 6 January 2020 Published Online First 20 February 2020

\title{
Non-communicable respiratory disease and air pollution exposure in Malawi: a prospective cohort study
}

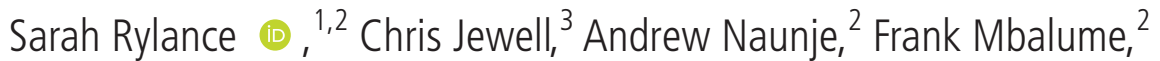 \\ John D Chetwood, ${ }^{4}$ Rebecca Nightingale, ${ }_{1}^{1}$ Lindsay Zurba, ${ }^{5}$ Graham Flitz, ${ }^{6}$ \\ Stephen B Gordon, ${ }^{1,2}$ Maia Lesosky, ${ }^{7}$ John R Balmes, ${ }^{6,8}$ Kevin Mortimer (i) ${ }^{1,9}$
}

\begin{abstract}
Rationale There are no population-based studies from sub-Saharan Africa describing longitudinal lung function in adults.

Objectives To explore the lung function trajectories and their determinants, including the effects of air pollution exposures and the cleaner-burning biomassfuelled cookstove intervention of the Cooking and Pneumonia Study (CAPS), in adults living in rural Malawi. Methods We assessed respiratory symptoms and exposures, spirometry and measured 48 -hour personal exposure to fine particulate matter $\left(\mathrm{PM}_{2.5}\right)$ and carbon monoxide (CO), on three occasions over 3 years. Longitudinal data were analysed using mixed-effects modelling by maximum likelihood estimation.
\end{abstract}

Measurements and main results We recruited 1481 adults, mean (SD) age 43.8 (17.8) years, including 523 participants from CAPS households (271 intervention; 252 controls), and collected multiple spirometry and air pollution measurements for 654 (44\%) and 929 (63\%), respectively. Compared with Global Lung Function Initiative African-American reference ranges, mean (SD) FEV (forced expiratory volume in $1 \mathrm{~s}$ ) and FVC (forced vital capacity) $z$-scores were -0.38 (1.14) and -0.19 (1.09). FEV and FVC were determined by age, sex, height, previous TB and body mass index, with FEV, declining by $30.9 \mathrm{~mL} /$ year $(95 \% \mathrm{Cl}: 21.6$ to 40.1$)$ and FVC by $38.3 \mathrm{~mL} /$ year ( $95 \% \mathrm{Cl}: 28.5$ to 48.1 ). There was decreased exposure to $\mathrm{PM}_{2.5}$ in those with access to a cookstove but no effect on lung function.

Conclusions We did not observe accelerated lung function decline in this cohort of Malawian adults, compared with that reported in healthy, non-smoking populations from high-income countries; this suggests that the lung function deficits we measured in adulthood may have origins in early life.

\section{INTRODUCTION}

Non-communicable respiratory diseases including chronic obstructive pulmonary disease (COPD) and asthma are a growing global concern, particularly in low-income and middle-income countries. ${ }^{1-3}$ Air pollution, including exposure to tobacco smoke, outdoor and household air pollutants, and occupational exposure to dust and fumes, is considered a major risk factor for non-communicable respiratory disease development and exacerbations. ${ }^{14}$ However, conflicting findings from recent studies

\section{Key messages}

What is the key question?

- Are the low lung volumes previously reported in adults from Malawi a result of impaired lung development in early life or accelerated lung function decline in adulthood or both, and does biomass smoke exposure influence the rate of decline in the same way as tobacco smoke exposure?

\section{What is the bottom line?}

- In an adult population with high biomass smoke exposure, we found rates of lung function decline comparable with healthy nonsmokers in high-income countries and lung function z-scores consistent with those reported in children from the same rural Malawian community.

\section{Why read on?}

- We report the first longitudinal lung function data from a population-representative cohort in sub-Saharan Africa: the results suggest that exposure to biomass fuel smoke may be less harmful than exposure to tobacco smoke or traffic-related air pollution, as reported in highincome settings.

have cast uncertainty over the specific role of household air pollution in COPD development. ${ }^{56}$ Approximately 3 billion people worldwide rely on highly polluting biomass fuels for cooking, heating and lighting. ${ }^{7}$ It is therefore a global public health priority to better understand the impact of household air pollution on non-communicable respiratory disease morbidity and mortality.

The lung function trajectories of adults from subSaharan Africa (sSA) are largely undescribed; limited published data relate to cohorts from South Africa with HIV-infection and occupational silica dust exposure. $^{89}$ There are no data from populationrepresentative cohorts in SSA; it is not known whether adults exposed to biomass-related air pollution would experience accelerated age-related decline in lung function and therefore an increased risk of developing obstructive airways diseases as occurs in those exposed to tobacco smoke. ${ }^{1011}$ 
The cross-sectional BOLD (Burden of Obstructive Lung Disease) study, conducted in urban Blantyre, Malawi found unexpectedly high rates of decreased forced vital capacity (FVC) and high levels of self-reported exposure to biomass smoke. ${ }^{12}$ The finding of a high burden of low FVC was concerning given the association between this and increased mortality. ${ }^{13}$ To further explore this phenomenon, we did a second study in rural Chikhwawa, Malawi (entitled BOLD-Chikhwawa) with the same protocol as the Blantyre BOLD study, but with the addition of measurement of personal exposure to air pollutants: carbon monoxide $(\mathrm{CO})$ and fine particulate matter $<2.5 \mu \mathrm{m}\left(\mathrm{PM}_{2.5}\right){ }^{14}$ We found comparably high rates of spirometric abnormalities, with decreased FVC seen in 35\% of participants, but no association between spirometric outcomes and exposure to $\mathrm{CO}$ or $\mathrm{PM}_{25}$ despite high levels of air pollution. Participants were from village communities which also participated in the Cooking and Pneumonia Study (CAPS), a cluster randomised trial of a cleaner-burning biomass-fuelled cookstove. ${ }^{15}$ Secondary analysis of adults from a subset of CAPS households found no difference in respiratory symptoms, lung function or personal air pollution exposures between intervention and control groups, but these analyses were done using cross-sectional data that were collected only a short time after introduction of the intervention-it is not known whether the rate of decline in lung function over time would be different between the trial arms. ${ }^{14}$

In this paper, we report the findings of lung function and personal air pollutant exposure monitoring during 3 years of follow-up for the BOLD-Chikhwawa cohort, to explore the determinants of lung function trajectories, including the effect of the CAPS cookstove intervention, in adults living in rural Malawi.

\section{METHODS}

\section{Setting}

Chikhwawa is a rural district, approximately $50 \mathrm{~km}$ south of Blantyre, on the Shire River valley. During the study period, this district experienced severe flooding and crop failures. CAPS recruited children aged $<4.5$ years in Chikhwawa between December 2013 and August 2015; intervention households received two cleaner-burning biomass-fuelled cookstoves, a solar panel to charge the stove-fan battery and user training at the time of randomisation. Those in the control arm continued using traditional cooking methods, mostly open fires, but received cookstoves at the end of the CAPS follow-up in May 2016.
BOLD-Chikhwawa was a separate study, recruiting adults from the same village communities as CAPS: not all BOLDChikhwawa participants were enrolled in CAPS. Figure 1 shows the timeline of CAPS and BOLD-Chikhwawa activities.

\section{Participants}

Age-stratified and gender-stratified population-representative sample of adults from 50 villages in Chikhwawa was taken as previously described. ${ }^{14}$ Written informed consent (or witnessed thumbprint) was obtained, with the information provided in the local language, Chichewa.

\section{Procedures}

Fieldworkers conducted follow-up visits in the community, approximately 1 and 2 years after enrolment, according to BOLD study standardised operating procedures, to collect questionnaires, spirometry and personal air pollution exposure data. ${ }^{16}$ Fieldworkers administered an abbreviated version of the BOLD study questionnaire in Chichewa, and measured height and weight.

BOLD Centre-certified fieldworkers conducted spirometry according to European Respiratory Society(ERS)/American Thoracic Society (ATS) standards using an EasyOne Spirometer (ndd Medical Technologies; Zurich, Switzerland), before and after administration of $200 \mu \mathrm{g}$ of Salbutamol via Volumatic spacer. ${ }^{17}$ Spirometry overreading was performed by an independent technician, according to the BOLD criteria for acceptability and repeatability.

After completing the questionnaire and spirometry assessment, participants were given an Indoor Air Pollution (IAP) 5000 Series Monitor (Aprovecho Research Centre, Oregon, USA) which they were instructed to wear in a small backpack during the day and to keep beside their sleeping mat at night, to estimate personal exposure to $\mathrm{PM}_{2.5}$ and $\mathrm{CO}$ over a 48 -hour period. These monitors continuously sample air from the breathing zone, and $\mathrm{PM}_{2.5}$ and $\mathrm{CO}$ are measured using a light-scattering photometer and electrochemical cell CO sensor, respectively. Fieldworkers encouraged compliance with personal exposure monitoring during frequent community visits. IAP traces with outlying $\mathrm{PM}_{2,5}$ or $\mathrm{CO}$ values (extremely high or low) were visually inspected for expected daily variation in exposure: traces without variability, suggesting that backpacks had not been worn, were excluded from the analysis.

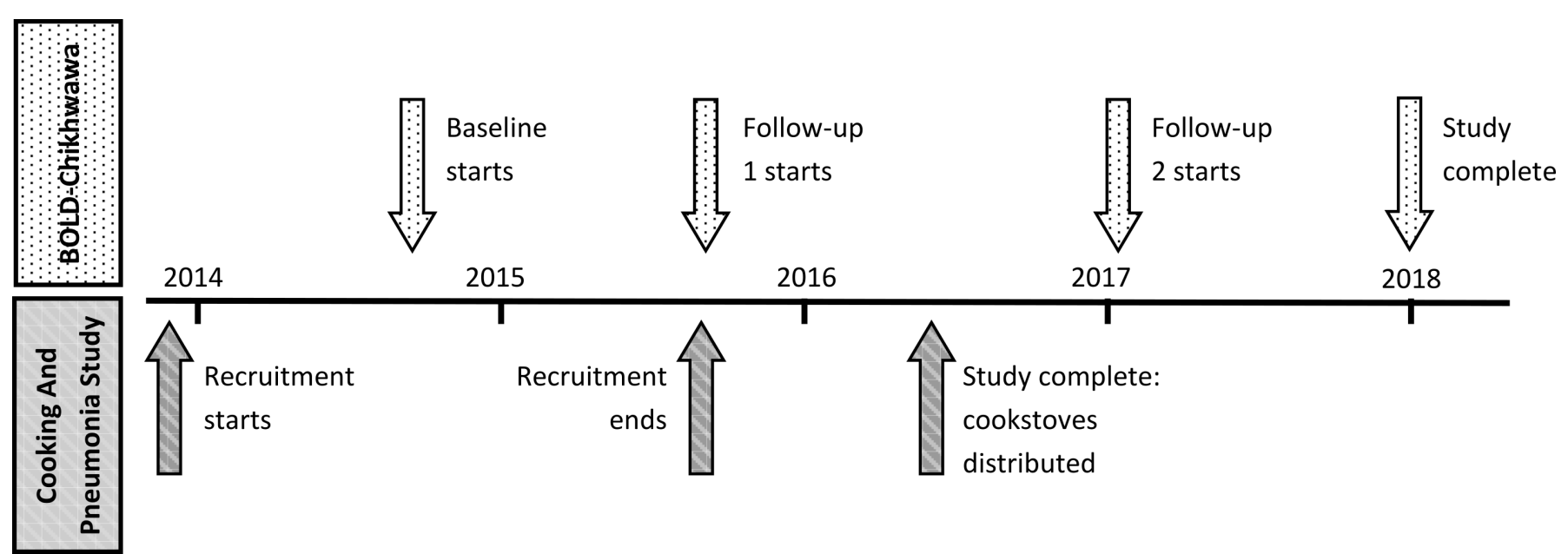

Figure 1 Timeline showing CAPS and BOLD-Chikhwawa activities. BOLD, Burden of Obstructive Lung Disease; CAPS, Cooking and Pneumonia Study. 


\begin{tabular}{|c|c|c|c|}
\hline & \multicolumn{3}{|l|}{$\%(95 \% \mathrm{Cl})$} \\
\hline & $\begin{array}{l}\text { Baseline } \\
(\mathrm{n}=1481)\end{array}$ & $\begin{array}{l}\text { Follow-up } 1 \\
(\mathrm{n}=1090)\end{array}$ & $\begin{array}{l}\text { Follow-up } 2 \\
(\mathrm{n}=989)\end{array}$ \\
\hline \multicolumn{4}{|l|}{ Respiratory symptoms } \\
\hline $\begin{array}{l}\text { Cough: Do you usually cough when you } \\
\text { do not have a cold? }\end{array}$ & $\begin{array}{l}11.1 \\
(9.6 \text { to } 12.9)\end{array}$ & $\begin{array}{l}10.1 \\
(8.4 \text { to } 12.0)\end{array}$ & $\begin{array}{l}25.3 \\
\text { (22.6 to } 28.1)\end{array}$ \\
\hline $\begin{array}{l}\text { Sputum: Do you usually bring up phlegm } \\
\text { from your chest when you do not have } \\
\text { a cold? }\end{array}$ & $\begin{array}{l}2.6 \\
\text { (1.8 to } 3.5)\end{array}$ & $\begin{array}{l}4.9 \\
(3.7 \text { to } 6.3)\end{array}$ & $\begin{array}{l}11.1 \\
\text { (9.2 to } 13.2 \text { ) }\end{array}$ \\
\hline $\begin{array}{l}\text { Wheeze: Have you had wheezing/ } \\
\text { whistling in your chest in the last } \\
12 \text { months, in the absence of a cold? }\end{array}$ & $\begin{array}{l}1.6 \\
\text { (1.0 to } 2.3)\end{array}$ & $\begin{array}{l}1.7 \\
(1.0 \text { to } 2.6)\end{array}$ & $\begin{array}{l}3.0 \\
\text { (2.1 to } 4.3)\end{array}$ \\
\hline $\begin{array}{l}\text { MRC dyspnoea II: Are you troubled by } \\
\text { shortness of breath when hurrying on the } \\
\text { level or walking up a slight hill? }\end{array}$ & $\begin{array}{l}1.6 \\
\text { (1.0 to } 2.3)\end{array}$ & $\begin{array}{l}6.6 \\
(5.2 \text { to } 8.2)\end{array}$ & $\begin{array}{l}11.8 \\
(9.9 \text { to } 14.0)\end{array}$ \\
\hline $\begin{array}{l}\text { Functional limitation: Have breathing } \\
\text { problems interfered with your usual daily } \\
\text { activities? }\end{array}$ & $\begin{array}{l}2.9 \\
\text { (2.1 to } 3.9)\end{array}$ & $\begin{array}{l}5.7 \\
(4.4 \text { to } 7.2)\end{array}$ & $\begin{array}{l}7.1 \\
\text { (5.6 to } 8.9)\end{array}$ \\
\hline $\begin{array}{l}\text { Any respiratory symptom (any of the } \\
\text { above five symptoms) }\end{array}$ & $\begin{array}{l}13.6 \\
\text { (11.9 to } 15.4)\end{array}$ & $\begin{array}{l}19.6 \\
\text { (17.3 to } 22.1)\end{array}$ & $\begin{array}{l}36.2 \\
\text { (33.3 to } 39.4)\end{array}$ \\
\hline \multicolumn{4}{|l|}{ Self-reported exposures } \\
\hline Current smoker & $\begin{array}{l}13.9 \\
(12.2 \text { to } 15.8)\end{array}$ & $\begin{array}{l}11.6 \\
\text { (9.7 to } 13.6)\end{array}$ & $\begin{array}{l}12.9 \\
(10.9 \text { to } 15.2)\end{array}$ \\
\hline Previous TB & $\begin{array}{l}3.2 \\
(2.3 \text { to } 4.2)\end{array}$ & $\begin{array}{l}3.0 \\
\text { (2.1 to } 4.2)\end{array}$ & $\begin{array}{l}2.6 \\
\text { (1.7 to } 3.8)\end{array}$ \\
\hline
\end{tabular}

$\mathrm{TB}$, tuberculosis.

\section{Variables}

Clinical outcomes were assessed by the questions detailed in table 1. Raw forced expiratory volume in $1 \mathrm{~s}\left(\mathrm{FEV}_{1}\right)$ and FVC values were used as continuous variables in the longitudinal analysis. Lung function parameters were compared with age, sex and height-standardised global lung initiative (GLI) reference ranges for African-Americans and NHANES III reference ranges for Caucasians and African-Americans. ${ }^{18}{ }^{19}$ Restriction was defined as FVC below the lower limit of normal (LLN), and obstruction as $\mathrm{FEV}_{1} / \mathrm{FVC}$ ratio below the LLN; values below the fifth centile in a healthy, non-smoking reference population.

Exposures included estimated personal exposure to $\mathrm{PM}_{2.5}$ and $\mathrm{CO}$, and questionnaire assessment of smoking status and previous tuberculosis. At baseline, first and second follow-up, participants were classed as having access to a cookstove if their household had been given a cleaner-burning biomass-fuelled cookstove by the CAPS study team prior to data collection.

Baseline $\mathrm{PM}_{2.5}$ and CO levels were zeroed at the 0.1th percentile of values obtained during each monitoring period. Observations were included if $>24$ hours were recorded, with recording truncated into 24-hour periods to reflect daily variation in personal exposure patterns, and only full 24-hour periods analysed. Log mean 24-hour $\mathrm{PM}_{2.5}$ and $\mathrm{CO}$ estimates were used for mixed-effects modelling.

Potential effect modifiers: body mass index (BMI) and/or height and weight, age, years of education and sex, were evaluated as fixed covariates in the FEV 1 and FVC linear mixedeffects models.

\section{Study size}

A total of 3000 adults were initially invited to enrol in the baseline BOLD-Chikhwawa cohort. Participants were followed up if they had completed a baseline questionnaire (1481 participants) and were included in the longitudinal lung function analysis if they had at least two valid spirometry assessments during the study period.

\section{Statistical methods}

Descriptive analysis was performed, with the Student $t$ test and Pearson's $\chi^{2}$ to compare continuous and categorical data.

Participants with incomplete data (lost-to-follow-up or failing to complete spirometry) were compared with those with complete data using $\chi^{2}$ and Student $t$ tests. Positive associations $(\mathrm{p}<0.2)$ on bivariate analysis were explored in multivariable logistic regression.

Two separate mixed-effects models were developed for the analysis of repeated exposure and lung function outcomes. In the log-linear exposure models, repeated estimates (mean 24 hours $\mathrm{CO}$ and $\mathrm{PM}_{2.5}$ ) from individuals were accounted for using an individual-level random effect, with an additional random-effect accounting for clustering of 24-hour measurements within 48-hour monitoring periods. Fixed-effect covariates were selected sequentially to determine the optimum model fit by likelihood ratio testing under maximum likelihood estimation (MLE), with the calculation of parameter estimates, standard errors and $\mathrm{p}$ values (see the online supplementary tables S2 and S3). Harmonic terms were included in the exposure models to account for any possible effect of seasonality on the outcome measures. This was implemented by including sinusoidal functions (sine and cosine terms) of time with a period of 1 year.

Longitudinal lung function $\left(\mathrm{FEV}_{1}\right.$ and $\left.\mathrm{FVC}\right)$ linear models included the fitted $\mathrm{CO}$ and $\mathrm{PM}_{2.5}$ values from the exposure model as fixed covariates; an average value was calculated where participants had multiple periods of exposure monitoring. Fixed-effect covariates were sequentially assessed by likelihood ratio testing under MLE (see the online supplementary tables S4 and S5), with interaction terms to explore the change in lung function over time. The final regression equations used in the exposure and lung function analysis are included in the online supplementary text $\mathrm{S} 1$.

Analyses were conducted using R V.3.4.1 statistical software.

\section{RESULTS}

Between August 2014 and July 2015, 1481 adults were enrolled in the study at baseline and followed up on two subsequent occasions. ${ }^{14}$ Three-quarters $(75 \%, \mathrm{n}=1090)$ were reassessed during the first follow-up period (August 2015-November 2016) and two-thirds $(67 \%, \mathrm{n}=989)$ during the second follow-up period (January 2017-November 2017) with data collected as shown in figure 2. Demographic data for participants with or without a questionnaire, spirometry or exposure monitoring are shown in the online supplementary table S1. Participants completing the second follow-up visit were more likely to be women (OR ( $95 \% \mathrm{CI}): 1.88$ (1.50 to 2.37$)$, and to have spent fewer years in education (OR (95\% CI): 0.96 (0.93 to 0.99$)$ ).

Spirometry was attempted by 950/1481 (64\%), 628/1090 $(58 \%)$ and 571/989 (58\%), and personal air pollution exposure monitoring completed for 1029/1481 (69\%), 830/1090 (76\%) and $811 / 989(82 \%)$ at baseline, first and second follow-ups, respectively (figure 2). Multiple spirometry measurements were available for 654/1481 (44\%) of participants, whereas 413 (28\%) had only one spirometry measurement and 413 (28\%) had none. Personal air pollution exposure was estimated on more than one occasion for 929/1481 (63\%) of participants, whereas $401(27 \%)$ had only one episode of monitoring and 151 $(10 \%)$ had none. 


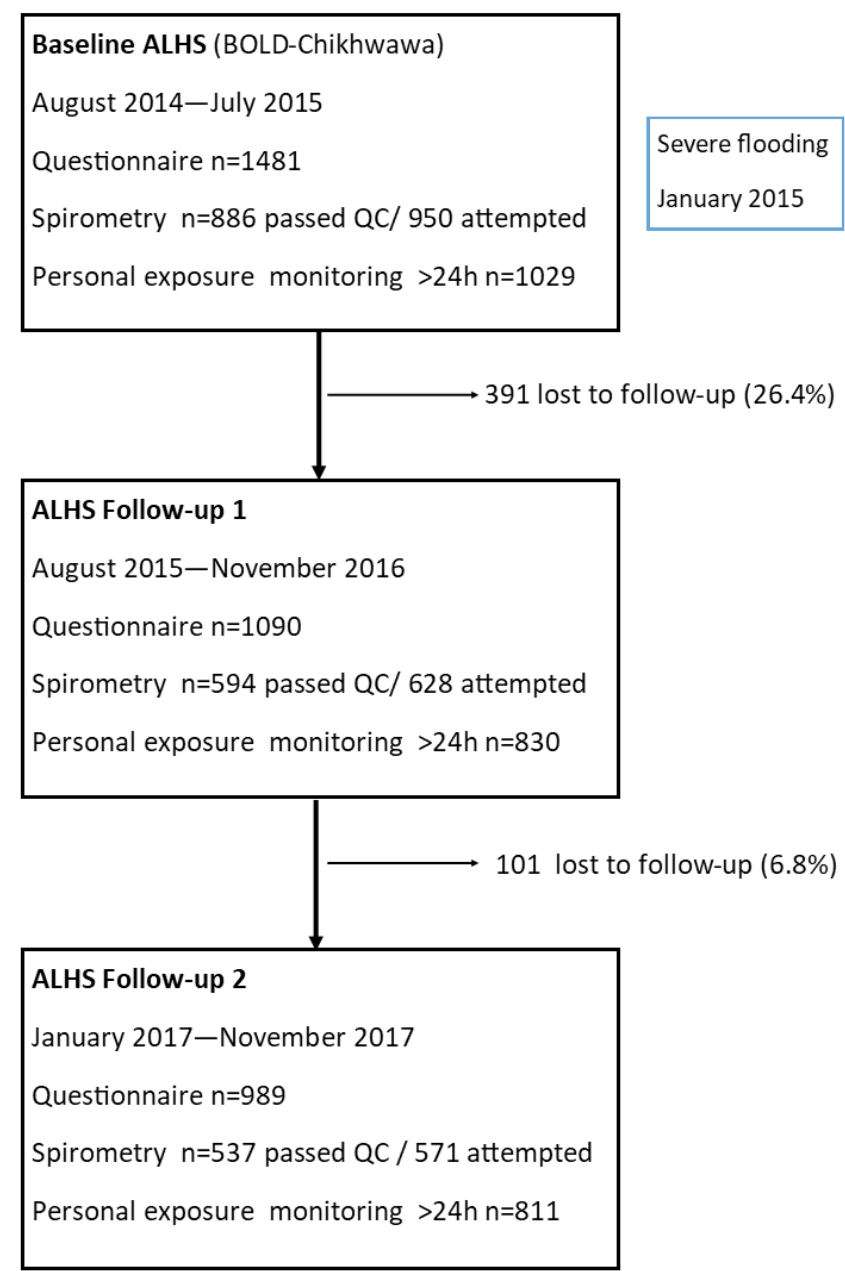

Figure 2 Participant flow diagram.

At baseline, the cohort included 424 participants from CAPS households: this rose to 523 participants (271 from intervention and 252 from control households) as CAPS continued to recruit until August 2015.

The baseline demographics of the cohort have been previously reported. ${ }^{14}$ In brief, at baseline the mean (SD) age of participants was 43.8 (17.8) years, 57\% were women and all households $(99.8 \%)$ used biomass fuels for cooking. One third had never attended school and half had not been educated beyond the primary school level.

The frequency of reported respiratory symptoms increased greatly over the course of the study (table 1): overall $13.6 \%$ (95\% CI: 11.9 to 15.4 ) of participants reported respiratory symptoms at baseline compared with $36.2 \%$ (95\% CI: 33.3 to 39.4 ) at the final follow-up. Self-reported rates of smoking and TB did not change over time; current smoking was reported by $13.9 \%$ and $12.9 \%$, and previous TB infection reported by $3.2 \%$ and $2.6 \%$, at the baseline and final follow-up, respectively.

\section{Personal exposure monitoring}

A total of 1768 personal exposure monitoring episodes lasted $>48$ hours, and a further 902 lasted between 24 and 48 hours. Within episodes of $>48$ hours, there was fair correlation between the first and second 24-hour periods, for both $\mathrm{PM}_{2.5}$ (adjusted $R^{2}=0.68$ ) and CO (adjusted $R^{2}=0.59$ ). Correlation between exposures to the two air pollutant measures (mean $\mathrm{PM}_{2.5}$ and
Table 2 Estimated risk ratios and 95\% Cls for fixed-effects covariates included in final air pollutant exposure log-linear mixedeffect models

\begin{tabular}{lll}
\hline & $\mathrm{PM}_{2.5}\left(\mu \mathrm{g} / \mathrm{m}^{3}\right)$ & $\mathrm{CO}(\mathrm{ppm})$ \\
\hline Sex & $1.27(1.13$ to 1.42$)$ & $1.60(1.51$ to 1.72$)$ \\
Current smoking & - & $1.22(1.12$ to 1.34$)$ \\
Seasonality: cosine function & - & $0.85(0.81$ to 0.89$)$ \\
Seasonality: sine function & - & $0.99(0.96$ to 1.03$)$ \\
Access to cookstove & $0.85(0.75$ to 0.97$)$ & - \\
\hline CO, carbon monoxide; $\mathrm{PM}_{2.5^{\prime}}$ fine particulate matter. &
\end{tabular}

CO), analysed for a total of 443824 hours monitoring periods was poor (adjusted $R^{2}=0.027$ ).

Overall, the 24 hours median personal $\mathrm{PM}_{25}$ and CO exposures were $77.0 \mu \mathrm{g} / \mathrm{m}^{3}$ (IQR, 42.8-153.1) and $1.27 \mathrm{ppm}$ (IQR, 0.79-2.05), respectively. Personal $\mathrm{PM}_{2.5}$ (median (IQR)) was $71.7 \mu \mathrm{g} / \mathrm{m}^{3}(42.8-128.0), 84.6 \mu \mathrm{g} / \mathrm{m}^{3}(45.9-175.7)$ and $75.9 \mu \mathrm{g} /$ $\mathrm{m}^{3}$ (40.1-176.4) at baseline, first and second follow-up, respectively. Personal CO exposure (median (IQR)) was $1.26(0.79-$ 2.07) ppm, $1.33(0.81-2.22) \mathrm{ppm}$ and $1.22(0.75-1.90) \mathrm{ppm}$, at baseline, first and second follow-up, respectively.

In total, 4377 24-hour monitoring periods with complete covariate data from 1304 individuals were included in mixedeffects exposure models, with $\mathrm{CO}$ and $\mathrm{PM}_{2.5}$ as the response variables. In the final $\mathrm{CO}$ model, we found strong evidence that female sex, current smoking status and seasonality were associated with the CO level (tables 2 and online supplementary table S2). In the final $\mathrm{PM}_{2.5}$ model, female sex was associated with increased $\mathrm{PM}_{25}$ and access to a cookstove with decreased $\mathrm{PM}_{2.5}$ (risk ratio $0.85 ; 95 \% \mathrm{CI}: 0.75$ to 0.97 ) (tables 2 and online supplementary table $\mathrm{S} 3$ ).

\section{Spirometry}

Of those attempting spirometry, ERS/ATS standards were achieved by $886 / 950$ (93.3\%), 594/628 (94.6\%) and 537/571 $(94.0 \%)$ at baseline, first and second follow-up visits, respectively (figure 2). On bivariate analysis, factors associated with failing to complete spirometry were: older age, lower BMI, female sex, current smoking, cough or any respiratory symptoms. In logistic multivariable analysis, participants who were women (OR (95\% CI), $0.52(0.39-0.71))$, older (OR (95\% CI), $0.97(0.96-0.98))$ or with a lower BMI (OR $(95 \% \mathrm{CI}), 1.09$ (1.04-1.14)) were significantly less likely to complete spirometry. Participants with longitudinal spirometry data had reduced lung function at baseline, compared with those who performed spirometry on only one occasion: mean (SD) FEV z-score -0.48 (1.03) vs -0.22 (1.28), mean (SD) FVC z-score -0.33 (1.01) vs 0.03 (1.19), respectively.

Best post-bronchodilator traces were analysed for 1068 participants who completed at least one spirometry session to ERS/ATS standards. Overall, mean (SD) FEV 1 and FVC were 2.55 (0.64) $\mathrm{L}$ and $3.16(0.73) \mathrm{L}$, respectively, with a mean (SD) $\mathrm{FEV}_{\mathrm{f}} / \mathrm{FVC}$ ratio of $0.80(0.09)$ (table 3). When compared with GLI AfricanAmerican reference ranges, mean (SD) $\mathrm{FEV}_{1}, \mathrm{FVC}$ and $\mathrm{FEV}_{1} /$ FVC ratio z-scores were $-0.38(1.14),-0.19(1.09)$ and -0.37 (1.04), respectively, with spirometric obstruction seen in $11.2 \%$ (95\% CI: $9.4 \%$ to $13.2 \%$ ) and low FVC in $8.1 \%$ (95\% CI: $6.5 \%$ to $9.9 \%)$. Rates of obstruction were similar when NHANES Caucasian reference ranges were used (11.5\% (95\% CI: 9.6\% to $13.5 \%)$ ), but considerably more-approximately $50 \%$-of 
Table 3 Best post-bronchodilator spirometry values* and classification by GLI and NHANES reference ranges for 1068 participants

\begin{tabular}{|c|c|c|}
\hline \multicolumn{3}{|c|}{ Spirometry value } \\
\hline \multirow[t]{3}{*}{ Raw } & Mean (SD) FEV ${ }_{1}, \mathrm{~L}$ & $2.55(0.64)$ \\
\hline & Mean (SD) FVC, L & $3.16(0.73)$ \\
\hline & Mean (SD) $\mathrm{FEV}_{1} / \mathrm{FVC}$ ratio & $0.80(0.09)$ \\
\hline \multirow[t]{3}{*}{ Z-scorest } & Mean (SD) FEV ${ }_{1} z$-score & $-0.38(1.14)$ \\
\hline & Mean (SD) FVC z-score & $-0.19(1.09)$ \\
\hline & Mean (SD) FEV $/$ FVC ratio z-score & $-0.37(1.04)$ \\
\hline Classification & & $\begin{array}{l}\% \text { of Population } \\
(95 \% \mathrm{Cl})\end{array}$ \\
\hline \multirow[t]{3}{*}{ Obstruction } & $\mathrm{FEV}_{1} / \mathrm{FVC}<\mathrm{LLN}$ GLI African-American & 11.2 (9.4 to 13.2 ) \\
\hline & $\mathrm{FEV}_{1} / \mathrm{FVCC}<\mathrm{LLN}$ NHANES African-American & 11.5 (9.6 to 13.5$)$ \\
\hline & $\mathrm{FEV}_{1} / \mathrm{FVC}<\mathrm{LLN}$ NHANES Caucasian & $9.8(8.1$ to 11.7$)$ \\
\hline \multirow[t]{3}{*}{ Restriction } & FVC < LLN GLI African-American & 8.1 (6.5 to 9.9$)$ \\
\hline & FVC $<$ LLN NHANES African-American & 7.7 (6.2 to 9.5$)$ \\
\hline & FVC <LLN NHANES Caucasian & 49.7 (46.7 to 52.8$)$ \\
\hline
\end{tabular}

tZ-scores calculated using GLI African-American reference ranges.

* For participants with spirometry measured at more than one time point, the best FEV , and FVC values were analysed.

$\mathrm{FEV}_{1}$, forced expiratory volume in $1 \mathrm{~s}$; FVC, forced vital capacity; GLI, global lung initiative; LLN, lower limit of normal.

participants were classified as having a low FVC (49.7\% (95\% CI: $46.7 \%$ to $52.8 \%)$.

Overall, the annual rate of lung function decline was $30.9 \mathrm{ml}$ (95\% CI: 21.6 to 40.1 ) for $\mathrm{FEV}_{1}$ and $38.3 \mathrm{ml} \mathrm{(95 \%} \mathrm{CI:} 28.5$ to 48.1) for FVC. Age, sex, height, previous TB infection and BMI were included in the final mixed-effects models as significant fixed-effect covariates for $\mathrm{FEV}_{1}$ and FVC (all $\mathrm{p}<0.001$, online supplementary table S4 and S5), although they did not affect the rate of lung function decline. Current smoking, access to a cookstove, PM2.5 and CO exposure levels did not significantly improve either model. Decreased $\mathrm{FEV}_{1}$ and FVC were associated with increasing age, female sex, previous TB infection and decreased height and BMI (table 4).

\section{DISCUSSION}

This is the first prospective cohort study to report longitudinal lung function and personal exposure to air pollution in an sSA

Table 4 Parameter estimates for multiple fixed-effects covariates included in final FEV ${ }_{1}$ and FVC linear mixed-effect models*

\begin{tabular}{|c|c|c|c|c|}
\hline & \multicolumn{2}{|l|}{$\mathrm{FEV}_{1}(\mathrm{~mL})$} & \multicolumn{2}{|l|}{$\mathrm{FVC}(\mathrm{mL})$} \\
\hline & Estimate & $95 \% \mathrm{Cl}$ & Estimate & $95 \% \mathrm{Cl}$ \\
\hline Time (years) & -30.9 & -40.1 to 21.6 & -38.3 & -48.1 to -28.5 \\
\hline Age (years) & -18.7 & -20.4 to -16.9 & -11.0 & -13.0 to -9.1 \\
\hline Sex (female) & -500.1 & -566.6 to -433.6 & -678.0 & $\begin{array}{l}-751.4 \text { to } \\
-604.7\end{array}$ \\
\hline Height $(\mathrm{cm})$ & 23.6 & 19.9 to 27.3 & 32.8 & 28.7 to 36.9 \\
\hline Previous TB (yes) & -404.9 & -539.7 to -230.2 & -334.2 & $\begin{array}{l}-526.6 \text { to } \\
-141.8\end{array}$ \\
\hline BMI & 21.9 & 13.8 to 30.0 & 21.3 & 12.4 to 30.2 \\
\hline
\end{tabular}

${ }^{*}$ Models include FEV ${ }_{1}$ and FVC data from 950 individuals, including 654 with two or more lung function measurements

$\mathrm{BMI}$, body mass index; $\mathrm{FEV}_{1}$, forced expiratory volume in 1 second; $F \mathrm{FC}$, forced vital capacity; TB, tuberculosis. population. The main findings were that: $\mathrm{FEV}_{1}$ and $\mathrm{FVC}$ were determined by age, sex, height, previous $\mathrm{TB}$ and $\mathrm{BMI}$, whereas there was no evidence of accelerated lung function decline (30.9 $\mathrm{mL} \mathrm{FEV}_{1}$ and $38.3 \mathrm{~mL} \mathrm{FVC} \mathrm{annual} \mathrm{decrease)} \mathrm{as} \mathrm{might} \mathrm{have}$ been expected in this population compared with the natural agerelated decline reported in populations from Europe and the USA. ${ }^{10}$ Mean (SD) FEV 1 and FVC z-scores $(-0.38$ (1.14) and $-0.19(1.09)$ ) were comparable with those previously reported for children from this community adding to evidence that spirometric abnormalities in adults have their origins in early life. ${ }^{20}$ Lung function was not associated with exposure to $\mathrm{CO}, \mathrm{PM}_{25}$ or access to a cookstove. Estimated $\mathrm{CO}$ and $\mathrm{PM}_{2.5}$ correlated poorly and were associated with different covariates. Exposure to $\mathrm{PM}_{2.5}$ was increased in women and decreased by a factor of $0.85(95 \%$ CI: 0.75 to 0.97 ) in those with access to a cookstove. Exposure to $\mathrm{CO}$ was increased in women and current smokers and showed a seasonal trend.

We did not find evidence of accelerated lung function decline despite exposure to high levels of $\mathrm{PM}_{2.5}$. Previous studies exploring the impact of $\mathrm{PM}_{2.5}$ on lung function in high-income settings have focused on $\mathrm{PM}_{2.5}$ from ambient air pollution, particularly traffic-related air pollution (TRAP). Faster lung function decline was associated with increasing $\mathrm{PM}_{2.5}$ in longitudinal cohorts from the USA and Taiwan, the effects of other pollutants were not reported..$^{21}{ }^{22} \mathrm{~A}$ large multicentre metanalysis from the European ESCAPE cohorts did not find an association between air pollution and lung function decline but noted that $\mathrm{NO}_{2}$ was negatively associated with lung function. ${ }^{23}$ It is possible that the emissions from incomplete biomass combustion are less harmful to the airways than the many constituents (including nitrogen oxides) of TRAP.

Previous work from Malawi has reported lung function relative to NHANES III Caucasian reference values to facilitate comparison with other BOLD studies. ${ }^{12} 14$ In this analysis, we have additionally compared our data with African-American reference ranges (NHANES and GLI). The prevalence of reduced FVC varies greatly depending on which reference equation is used. ${ }^{24}$ The prognostic significance of markedly different predicted values in different ethnic populations is unclear. ${ }^{25}$ Reduced FVC is seen in restrictive lung disease, however a more detailed assessment of total lung capacity by plethysmography is needed to further characterise the pattern of lung defect seen in African populations.

The use of GLI reference ranges permitted direct comparison with spirometry data from children living in the same community. We recently reported lung function for children aged 6-8 years, living in Chikhwawa; $\mathrm{FEV}_{1}, \mathrm{FVC}$ and $\mathrm{FEV}_{1} / \mathrm{FVC}$ ratio z-scores were $-0.48(0.93),-0.30(0.96)$ and $-0.38(0.90)$, respectively, compared with GLI African-American reference ranges. ${ }^{20}$ The finding of similar $z$-scores in both the children and adults living in this community suggests that factors which influence lung growth and development act in early childhood before 6 years of age, perhaps even starting in-utero.

We found an increase in self-reported respiratory symptoms over the 3-year follow-up period but no changes in exposures (self-reported TB or smoking status, or measured $\mathrm{PM}_{2.5}$ or $\mathrm{CO}$ ). We speculate this is due to changes in reporting behaviour rather than a true change in symptom prevalence. During the CAPS period, the local community were exposed to messages about the health impact of air pollution and may have become sensitised to the issues of clean air and respiratory health. Participants became familiar with the same questions asked on repeated occasions: this may have led to a positive reporting bias. Alternatively, responses at baseline may have underreported symptom 
prevalence: a community survey in two rural districts in Central Malawi reported chronic respiratory symptoms in $22.5 \%$ of the population. ${ }^{26}$

Previous cookstove intervention trials have explored lung function in adult women only. ${ }^{27}{ }^{28}$ The RESPIRE randomised controlled trial in Guatemala reported a reduction in 48-hour personal $\mathrm{CO}$ exposure in the intervention group using a plancha woodstove but no effect on women's lung function at 12-18 months in an intention-to-treat analysis. ${ }^{28} \mathrm{~A}$ subsequent exposure-response analysis did find a significantly decreased rate of decline with decreased exposure to $\mathrm{CO} .{ }^{29}$ The use of a Patsari stove in rural Mexico was associated with a significantly decreased rate of lung function $\left(\mathrm{FEV}_{1}\right)$ decline in women compared with those cooking on open fires ( 31 vs $62 \mathrm{~mL}$ ), over 1 year of follow-up, but this effect was not observed on intention-to-treat analysis. ${ }^{27}$ This decrease in decline is comparable with that reported among ex-smokers, in the first year after quitting; their $\mathrm{FEV}_{1}$ trajectory showed half the rate of annual decline compared with those who continued to smoke ((mean \pm SD) $31 \pm 48$ vs $62 \pm 55 \mathrm{~mL}) .{ }^{30}$ Our finding of $\mathrm{FEV}_{1}$ annual decline of $30.9 \mathrm{~mL}$ is consistent with the ranges seen in non-smokers from various studies. ${ }^{11}$

Our findings would suggest that low lung volumes seen in Malawian adults are not a result of accelerated decline in lung function, but more likely a failure to reach maximal lung volumes in early adulthood, either due to low lung function at birth or suboptimal lung growth during early childhood. Low birth weight and prematurity are of particular relevance in Malawi; the country has the highest rate of preterm birth worldwide, and intrauterine growth restriction, in both term and preterm infants, is common in low-income countries due to maternal factors including young maternal age, short-interpregnancy intervals and congenital infections. ${ }^{31}{ }^{32}$ Adverse effects of prenatal exposure to household air pollution on infant lung function have been suggested by the recent GRAPHS trial in Ghana. ${ }^{33}$ The adverse effect of early respiratory infections on lung health in adulthood has long been recognised; such infections are common in ssA, particularly during the first year of life. ${ }^{3435}$

Several studies have used CO levels as a proxy for particulate matter, which is challenging to measure in the field in low-resource settings. However, respirable particulate matter $\leq 2.5 \mu \mathrm{m}\left(\mathrm{PM}_{2.5}\right)$ can reach the alveolar level in the lungs and is of greater interest when considering the adverse respiratory effects of air pollution. We found no association between $\mathrm{PM}_{25}$, $\mathrm{CO}$ or access to a cookstove and lung function. In keeping with findings from Peru, Nepal and Kenya, we observed poor correlation between $\mathrm{CO}$ and $\mathrm{PM}_{25}$ measurements and different explanatory covariates for the two pollutants in our exposure models. ${ }^{36}$ Although observed levels of exposure to both CO and $\mathrm{PM}_{2.5}$ exceeded WHO upper safety limits, the duration of these high exposures was brief and we speculate that adverse pulmonary effects are limited by the low intensity of exposure in rural Malawi where most cooking is done outdoors. Similarly, we found that current smoking was not associated with $\mathrm{FEV}_{1}$ in this population, likely reflecting the low intensity of tobacco use among smokers in this community; less than one-fifth of current or ex-smokers at baseline reported cigarette consumption of $>10$ pack years.

Strengths of our study include the collection of longitudinal lung function and personal air pollution exposure data in a rural cohort in one of the world's poorest countries; high-quality spirometry performed by BOLD-certified technicians, with external quality control of traces by an independent expert reviewer. Limitations include potential recall bias and highly variable responses to questionnaires, and bias introduced by those not attempting spirometry or lost to follow-up. Participants performing spirometry were younger and hence, it is likely that spirometric abnormalities, such as obstruction, which are associated with increasing age are likely to be under-represented. Throughout the study the team struggled with cultural beliefs that older members of the community were "too weak" or "physically unable" to attempt spirometry. One-third of participants from baseline were lost to follow-up by the end of the study; we were unable to ascertain the reasons for this due to limitations of the data collected, but comparison of the demographic data for those who remained in the study at each phase suggested that men and those with better education were more likely to be lost, reflecting the more economically active, mobile sector of society. We recognise that 3 years is a relatively short time period to track longitudinal changes in lung function but believe we would more likely observe any effect of the intervention during the CAPS study period when the use of the cookstoves was actively supported by a repair and maintenance programme. Given that the rate in decline in lung function we observed over 3 years was consistent with the rate of decline seen in healthy adults in Europe and North America, it seems likely that this observation is accurate and that a longer period of follow-up would not have yielded additional useful rate of decline information.

In conclusion, in our cohort of adults living in rural Malawi, we observed (a) reduced FVC compared with Caucasian reference populations, similar in relative magnitude to what we previously reported in children living in the same communities, (b) no evidence of accelerated decline in $\mathrm{FEV}_{1}$ or FVC and c) no effect of access to cleaner-burning cookstoves on lung function decline. We suggest that future efforts to improve the lung health of those living in the poorest parts of the world should focus on antenatal and early childhood interventions to maximise lung growth and development. Further research is required to define the prognostic significance of reaching adulthood with suboptimal lung volumes, regardless of the comparative reference range in terms of morbidity, mortality and associated socioeconomic costs.

\section{Author affiliations}

'Department of Clinical Sciences, Liverpool School of Tropical Medicine, Liverpool, UK ${ }^{2}$ Lung Health Group, Malawi Liverpool Wellcome Trust Clinical Research Programme,

Blantyre, Malawi

${ }^{3}$ CHICAS, University of Lancaster, Lancaster, UK

${ }^{4} J o h n$ Hunter Hospital, New Lambton Heights, New South Wales, Australia

${ }^{5}$ Education for Health Africa, Vereeniging, South Africa

${ }^{6}$ School of Public Health, University of California, Berkeley, California, USA

${ }^{7}$ Division of Epidemiology and Biostatistics, School of Public Health and Family Medicine, University of Cape Town, Rondebosch, Cape Town, South Africa

${ }^{8}$ Environmental Health Sciences Division, University of California San Francisco, San Francisco, California, USA

${ }^{9}$ Aintree University Hospitals NHS Foundation Trust, Liverpool, UK

Acknowledgements The authors thank the study participants, village leaders and community representatives, the study team in Chikhwawa, MLW and LSTM, the CAPS trial steering committee and data monitoring committee, the Malawi Ministry of Health, and the African Clean Energy (ACE) company for their valued contributions to making this work a success. They also acknowledge Professor Peter Burney and the BOLD Centre, for their contribution to the baseline dataset included in this analysis.

Contributors Design: $S R, K M$ and JB. Acquisition of data: $S R, R N, A N, F M, K M, G F$, JC and LZ. Analysis of data: SR, CJ, ML and RN. Interpretation of data: SR, CJ, JB and $\mathrm{KM}$. Supervision: $\mathrm{KM}, \mathrm{CJ}$ and $\mathrm{SG}$. Writing the manuscript, approval of the version to be published and agreement to be accountable for all aspects of the work: all authors

Funding This work was funded by a New Investigator Research Grant from the Medical Research Council (Ref: MR/L002515/1), a Joint Global Health Trials Grant from the Medical Research Council, UK Department for International Development and Wellcome Trust (Ref: MR/K006533/1) and the Medical Research Council Doctoral Training Programme at the Liverpool School of Tropical Medicine and University 
of Lancaster (Ref: MR/N013514/1) and US National Institute of Environmental Health Sciences (Ref: R56ES023566). The Malawi-Liverpool-Wellcome Trust Clinical Research Programme is funded by the Wellcome Trust (Ref: 206454). Additional support was provided by the NIHR Global Health Research Unit on Lung Health and TB in Africa at LSTM - 'IMPALA'. In relation to IMPALA (grant number 16/136/35) specifically: IMPALA was commissioned by the National Institute of Health Research using Official Development Assistance (ODA) funding. The views expressed in this publication are those of the author(s) and not necessarily those of the National Institute for Health Research or the Department of Health.

Competing interests None declared.

Patient consent for publication Not required.

Ethics approval The study was approved by the Malawi College of Medicine Research Ethics Committee (reference P.11/12/1308) and the Liverpool School of Tropical Medicine Research Ethics Committee (reference 12.40).

Provenance and peer review Not commissioned; externally peer reviewed.

Data availability statement Data are available upon reasonable request. Data analysis is ongoing for PhD thesis (SR: first author ORCID ID 0000-0001-64599073). Datasets will be made publicly available on completion of PhD.

Open access This is an open access article distributed in accordance with the Creative Commons Attribution 4.0 Unported (CC BY 4.0) license, which permits others to copy, redistribute, remix, transform and build upon this work for any purpose, provided the original work is properly cited, a link to the licence is given, and indication of whether changes were made. See: https://creativecommons.org/ licenses/by/4.0/.

ORCID iDs

Sarah Rylance http://orcid.org/0000-0001-6459-9073

Kevin Mortimer http://orcid.org/0000-0002-8118-8871

\section{REFERENCES}

1 Burney $P$, Jarvis $D$, Perez-Padilla R. The global burden of chronic respiratory disease in adults. Int J Tuberc Lung Dis 2015;19:10-20.

2 Adeloye D, Chan KY, Rudan I, et al. An estimate of asthma prevalence in Africa: a systematic analysis. Croat Med J 2013;54:519-31.

3 Beran D, Zar HJ, Perrin C, et al. Burden of asthma and chronic obstructive pulmonary disease and access to essential medicines in low-income and middle-income countries. Lancet Respir Med 2015;3:159-70.

4 Gordon SB, Bruce NG, Grigg J, et al. Respiratory risks from household air pollution in low and middle income countries. Lancet Respir Med 2014;2:823-60.

5 Amaral AFS, Patel J, Kato BS, et al. Airflow obstruction and use of solid fuels for cooking or heating: BOLD results. Am J Respir Crit Care Med 2018;197:595-610.

6 Siddharthan T, Grigsby MR, Goodman D, et al. Association between household air pollution exposure and chronic obstructive pulmonary disease outcomes in 13 lowand middle-income country settings. Am J Respir Crit Care Med 2018;197:611-20.

7 WHO. Who guidelines for indoor air quality: household fuel combustion. Geneva; 2014.

8 Gupte AN, Wong ML, Msandiwa R, et al. Factors associated with pulmonary impairment in HIV-infected South African adults. PLoS One 2017;12:e0184530.

9 Ross J, Ehrlich RI, Hnizdo E, et al. Excess lung function decline in gold miners following pulmonary tuberculosis. Thorax 2010;65:1010-5.

10 Lange P, Celli B, Agustí A, et al. Lung-Function trajectories leading to chronic obstructive pulmonary disease. N Engl J Med 2015;373:111-22.

11 Kerstjens HA, Rijcken B, Schouten JP, et al. Decline of FEV 1 by age and smoking status: facts, figures, and fallacies. Thorax 1997;52:820-7.

12 Meghji J, Nadeau G, Davis KJ, et al. Noncommunicable lung disease in sub-Saharan Africa. A community-based cross-sectional study of adults in urban Malawi. Am J Respir Crit Care Med 2016;194:67-76.

13 Burney P, Jithoo A, Kato B, et al. Chronic obstructive pulmonary disease mortality and prevalence: the associations with smoking and poverty--a BOLD analysis. Thorax 2014;69:465-73.
14 Nightingale R, Lesosky M, Flitz G, et al. Noncommunicable respiratory disease and air pollution exposure in Malawi (CAPS). A cross-sectional study. Am J Respir Crit Care Med 2019;199:613-21.

15 Mortimer K, Ndamala CB, Naunje AW, et al. A cleaner burning biomass-fuelled cookstove intervention to prevent pneumonia in children under 5 years old in rural Malawi (the cooking and pneumonia study): a cluster randomised controlled trial. The Lancet 2017;389:167-75.

16 Buist AS, Vollmer WM, Sullivan SD, et al. The burden of obstructive lung disease initiative (BOLD): rationale and design. COPD 2005;2:277-83.

17 Miller MR, Hankinson J, Brusasco V, et al. Standardisation of spirometry. Eur Respir J 2005;26:319-38.

18 Quanjer PH, Stanojevic S, Cole TJ, et al. Multi-Ethnic reference values for spirometry for the 3-95-yr age range: the global lung function 2012 equations. Eur Respir J 2012:40:1324-43.

19 Hankinson JL, Odencrantz JR, Fedan KB. Spirometric reference values from a sample of the general U.S. population. Am J Respir Crit Care Med 1999;159:179-87.

20 Rylance S, Nightingale R, Naunje A, et al. Lung health and exposure to air pollution in Malawian children (CAPS): a cross-sectional study. Thorax 2019;74:1070-7.

21 Guo C, Zhang Z, Lau AKH, et al. Effect of long-term exposure to fine particulate matter on lung function decline and risk of chronic obstructive pulmonary disease in Taiwan: a longitudinal, cohort study. Lancet Planet Health 2018;2:e114-25.

22 Rice MB, Ljungman PL, Wilker EH, et al. Long-Term exposure to traffic emissions and fine particulate matter and lung function decline in the Framingham heart study. Am 」 Respir Crit Care Med 2015;191:656-64.

23 Adam M, Schikowski T, Carsin AE, et al. Adult lung function and long-term air pollution exposure. escape: a multicentre cohort study and meta-analysis. Eur Respir $」$ 2015;45:38-50.

24 Obaseki DO, Erhabor GE, Awopeju OF, et al. Reduced forced vital capacity in an African population. prevalence and risk factors. Ann Am Thorac Soc 2017;14:714-21.

25 Rylance S, Mortimer K. Galloping Hooves in Africa: horse, zebra, or Wildebeest? Ann Am Thorac Soc 2017;14:624-5.

26 Banda HT, Thomson R, Mortimer K, et al. Community prevalence of chronic respiratory symptoms in rural Malawi: implications for policy. PLoS One 2017;12:e0188437.

27 Romieu I, Riojas-Rodríguez H, Marrón-Mares AT, et al. Improved biomass stove intervention in rural Mexico: impact on the respiratory health of women. Am J Respir Crit Care Med 2009;180:649-56.

28 Smith-Sivertsen T, Díaz E, Pope D, et al. Effect of reducing indoor air pollution on women's respiratory symptoms and lung function: the respire randomized trial, Guatemala. Am J Epidemiol 2009;170:211-20.

29 Pope D, Diaz E, Smith-Sivertsen T, et al. Exposure to household air pollution from wood combustion and association with respiratory symptoms and lung function in nonsmoking women: results from the respire trial, Guatemala. Environ Health Perspect 2015:123:285-92.

30 Scanlon PD, Connett JE, Waller LA, et al. Smoking cessation and lung function in mild-to-moderate chronic obstructive pulmonary disease. the lung health study. Am J Respir Crit Care Med 2000;161:381-90.

31 March of Dimes, PMNCH, Save the Children, WHO. Born too soon: the global action report on preterm birth. Geneva World Health Organisation; 2012.

32 Suhag A, Berghella V. Intrauterine growth restriction (IUGR): etiology and diagnosis. Curr Obstet Gynecol Rep 2013;2:102-11.

33 Lee AG, Kaali S, Quinn A, et al. Prenatal household air pollution is associated with impaired infant lung function with sex-specific effects. Evidence from graphs, a cluster randomized Cookstove intervention trial. Am J Respir Crit Care Med 2019;199:738-46.

34 Barker DJ, Godfrey KM, Fall C, et al. Relation of birth weight and childhood respiratory infection to adult lung function and death from chronic obstructive airways disease. BMJ 1991;303:671-5.

35 le Roux DM, Myer L, Nicol MP, et al. Incidence and severity of childhood pneumonia in the first year of life in a South African birth cohort: the Drakenstein child health study. The Lancet Global Health 2015;3:e95-103.

36 Klasen EM, Wills B, Naithani N, et al. Low correlation between household carbon monoxide and particulate matter concentrations from biomass-related pollution in three resource-poor settings. Environ Res 2015;142:424-31. 